\section{Clinical and Individual Variables in Children's Dental Fear: A School-Based Investigation}

\author{
Ethieli Rodrigues da Silveira1, Marília Leão Goettems², Flávio Fernando \\ Demarco $^{3}$, Marina Sousa Azevedo ${ }^{2}$
}

'Graduate Program in Dentistry, Dental School, UFPel - Universidade Federal de Pelotas, Pelotas, RS, Brazil ${ }^{2}$ Department of Social and Preventive Dentistry, Graduate Program in Dentistry, Dental School, UFPel - Universidade Federal de Pelotas, Pelotas, RS ${ }^{3}$ Department of Operative Dentistry, Graduate Program in Dentistry, Dental School, UFPel - Universidade Federal de Pelotas, Pelotas, RS

Correspondence: Flávio Fernando Demarco, Rua Gonçalves Chaves, 457, $5^{\circ}$ and., 96015-560 Pelotas, RS, Brasil. Tel.:+55-53-3222-6690. e-mail: ffdemarco@gmail.com

Key Words: child, dental fear, dental anxiety, epidemiology.

\section{Introduction}

Although a worldwide decrease in untreated dental caries in permanent and primary teeth have been observed, dental caries still are a major dental public health problem, affecting approximately 35\% permanent teeth and 9\% primary teeth of the world population (1) often leading to emotional, social and functional impairment. Dental caries occurrence may be influenced by socioeconomic, demographic, behavioral, biological and clinical conditions and avoidance to look for dental treatment is one major reason for the impairment of oral health (2). In dentistry, fear has been reported to be a significant aspect affecting attendance to dental care, since anxious people tend to avoid dental offices (3). The presence of dental fear in childhood may be a problem even for latter periods of life, because this feeling may persist for a long time (4). A negative experience or an inadequate first dental visit during childhood can lead a grown person to present high levels of dental fear (5).

Despite being an emotion considered inevitable and indispensable, constituting part of the physiological phenomenon of fight or flight, fear can lead a person to avoid or escape situations that are not really dangerous (4). The etiology of dental fear is multifactorial (2) and its prevalence is highly variable, from $6.1 \%$ (6) to $40 \%$ (7) and such large variation can be attributed to differences in study's designs and in the target population. There is evidence that dental fear or anxiety in children may be influenced by socioeconomic position, levels of dental caries (3), the child's personality and the social environment, and family behavior (8). The relationship between child's gender and dental fear is not completely unveiled, with contradictory results exhibited by the literature (9). Children's dental experience has also an important impact in dental fear occurrence, with higher prevalence observed in children who had never visited the dentist, who had frequently experienced dental pain and whose reason for the first dental visit was curative or urgency $(3,7,8)$. Also, dental fear can influence the behavior of children during dental treatment and this is especially important for pediatric dentists, who need their cooperation when carrying out dental treatments (3).

The age of the child plays a crucial role in the prevalence of dental fear $(3,10)$. Most studies of the factors affecting dental fear were focused in preschoolers. In a birth cohort, evaluating children at age 5, Torriani et al. (3) observed a high prevalence $(16.8 \%)$ of dental fear, more prevalent among children with dental caries and those who never attended the dentist's office. Even so, there are few studies addressing the dental fear and associated factors in schoolchildren. The transition from preschool phase to the school phase may display differences in the response to physical and emotional conditions. For example, there 
is no significant difference in dental pain reported for girls and boys at the age of 5 years, but when they are at age 12 , girls had significantly reported more pain than boys and the authors accounted this difference to the social conditioning and modulation by the age (11). Since dental fear is a subjective feeling it may be influenced by the emotional and physical events related to the growth process.

Therefore, the aim of this study was to assess the prevalence and associated factors influencing dental fear among schoolchildren aged 8-12 years old, attending private and public schools in southern Brazil. The tested hypothesis was that the occurrence of dental fear in this age range may be influenced by socioeconomic, demographic, behavioral and clinical characteristics.

\section{Material and Methods Sample}

This cross-sectional study was part of a comprehensive oral health survey carried out between September and December 2010, in Pelotas, a city in southern Brazil with 320,000 inhabitants. This study was performed on 8- to 12 -year-old children attending public and private schools. The 20 schools randomly selected were representative of the 25 private and 91 public schools in Pelotas in the year of collection, which had children in this age range attending these schools.

For the sample selection a two-stage stratified sample design was adopted. In the first stage, the primary units (schools) were selected. In order to ensure proportionality, five private and 15 public schools were randomly selected using a probability selection method. In second stage, five 2 nd to 6th grade classes were randomly selected in each school and all the students enrolled in these classes were initially eligible for the study. Physically and/or mentally disabled children were excluded from the study, based on information provided by parents or teachers. A previous published study describes the detailed methodological aspects (12).

The minimum sample size needed was estimated using the Epi Info 6.0 software (Centers for Disease Control and Prevention, Atlanta, GA, USA). Considering an estimated dental fear prevalence rate of $14.5 \%$, a $3 \%$ margin of error, a confidence level of 95\%, with 80\% power and 5\% Type I error probability, it was determined that at least 519 children should be included in the sample. The authors added $15 \%$ more to compensate potential loss or refusal and a sample size of 597 would be required. The sample size of this study $(1,202)$ was higher than the minimum required, because it was part of a large multidisciplinary study, which assessed many other outcomes related to oral health, nutrition status and physical activity levels among schoolchildren.

\section{Data Collection}

Data were collected using a parent's questionnaire, children's interviews and oral clinical examinations.

The children's dental fear outcome was assessed using an instrument with a single question (DAQ: Dental Anxiety Question) (13), with the following question for the children "Are you afraid of going to the dentist?". The possible answers were 'no', 'a little', 'yes, quite' and 'yes, very'. Participants who answered 'a little', 'yes, quite' and 'yes, very' were considered to have dental fear ('Yes') $(2,7)$. Questionnaires were sent to parents to obtain information about sociodemographic characteristics and children's oral health behavior. The level of parents' education was evaluated in terms of years of formal education and dichotomized in $<8$ years or $\geq 8$ years. Family income was collected in Brazilian currency (Real) and then categorized into quartiles. The first quartile comprised a family income up to $R \$ 510,00$ (approximately $U \$ 158$ ), the second quartile included incomes from $R \$ 511$ up to 740 (approximately \$229), in the third quartile were included incomes from $\mathrm{R} \$ 741$ up to 1200 (approximately \$372), and in the last quartile incomes above $R \$ 1,200$. The parents were also questioned if their children had ever visited the dentist during their lifetime and the answers were "yes" or "no".

After the parents returned the questionnaire, children were interviewed to provide information on demographic characteristics and oral health behavior. Children's gender and age (in years) were collected. The skin color was determined based on the Brazilian Institute of Geography and Statistics (IBGE) guidelines and then categorized as white or non-white. The children were also questioned about dental pain in the past six months and the answers were "yes" or "no". The daily brushing frequency was categorized in "two times or less" and "three times or more".

The clinical examination was conducted by six dentists using personal protective equipment, artificial light (headlamp), mirror and CPI periodontal probe, following WHO biosecurity directions (14). The examinations were performed in regular school chairs. Data regarding dental caries was collected using DMFT/dmtf (decayed, missing and filled teeth) index (14). For statistical analyses only the caries presence (decayed index) was considered, dichotomized in " 0 " or " $>1$ ", both in primary and in permanent teeth. Gingival bleeding index was assessed in 6 teeth (first molars and incisors) after probing four sites in each tooth in previously selected diagonal quadrants (12). Gingival bleeding was dichotomized in present or absent.

Children's interview and clinical examinations were carried out at the school. Schools were visited until no more than 10 percent of children were absent from data collection.

To ensure study reliability, a training and calibration 
process was performed. This process was divided in three parts, theoretical and practical training, clinical calibration and analysis of agreement. To test the applicability of the questionnaires, a pre-test was carried out with mothers and children in the study age range. After a theoretical explanation about clinical criteria and a brief examination in same age children, the fieldwork team was calibrated performing clinical examination in 20 children. The reliability of the calibration was assessed by kappa test.

Table 1. Sample distribution and prevalence of dental fear according to sociodemographic characteristics, and oral health behavior. Pelotas, Brazil, $2010(n=1,202)$

\begin{tabular}{|c|c|c|c|c|c|c|}
\hline \multirow{2}{*}{ Variable } & \multirow{2}{*}{ Categories } & \multicolumn{2}{|c|}{ Total } & \multicolumn{2}{|c|}{ Dental fear } & \multirow{2}{*}{$p$ value } \\
\hline & & $\mathrm{N}^{*}$ & $\%$ & $\mathrm{~N}$ & $\%$ & \\
\hline \multirow[b]{2}{*}{ Sex } & Male & 569 & 47.40 & 99 & 17.40 & \multirow{2}{*}{$<.001$} \\
\hline & Female & 633 & 52.60 & 197 & 31.12 & \\
\hline \multirow{5}{*}{ Age (years) } & 8 & & & & 27.37 & \multirow{5}{*}{$.180^{*}$} \\
\hline & 9 & 179 & 15.03 & 49 & 25.65 & \\
\hline & 10 & 308 & 25.76 & 79 & 24.75 & \\
\hline & 11 & 295 & 24.36 & 73 & 22.87 & \\
\hline & 12 & 258 & 21.39 & 59 & 22.22 & \\
\hline \multirow{2}{*}{ Skin color } & White & 162 & 13.46 & 36 & 23.67 & \multirow{2}{*}{.083} \\
\hline & Non-White & & & & 28.62 & \\
\hline \multirow{2}{*}{$\begin{array}{l}\text { Maternal } \\
\text { schooling (years) }\end{array}$} & $\geq 8$ & 849 & 72.85 & 201 & 21.40 & \multirow{2}{*}{.001} \\
\hline & $<8$ & 318 & 27.15 & 91 & 29.95 & \\
\hline \multirow{4}{*}{ Family income } & 1st (lowest) & & & & 33.81 & \multirow{4}{*}{$<.001^{*}$} \\
\hline & 2nd & 743 & 63.78 & 159 & 23.24 & \\
\hline & $3 r d$ & 424 & 36.22 & 127 & 21.48 & \\
\hline & 4th (highest) & & & & 16.80 & \\
\hline \multirow[b]{2}{*}{ Dental pain } & Absent & 244 & 23.72 & 41 & 22.03 & \multirow{2}{*}{.007} \\
\hline & Present & 270 & 26.13 & 58 & 29.11 & \\
\hline \multirow{2}{*}{ Dental visit } & Yes & 241 & 23.24 & 56 & 19.89 & \multirow{2}{*}{$<.001$} \\
\hline & No & 278 & 26.90 & 94 & 39.31 & \\
\hline \multirow{2}{*}{ Dental caries $(\mathrm{D} / \mathrm{d})$} & 0 & & & & 23.88 & \multirow{2}{*}{$<.001$} \\
\hline & $\geq 1$ & & & & 36.44 & \\
\hline \multirow{2}{*}{$\begin{array}{l}\text { Gingival } \\
\text { bleeding }\end{array}$} & Absent & 767 & 64.30 & 169 & 24.79 & \multirow{2}{*}{.950} \\
\hline & Present & 426 & 35.70 & 124 & 24.60 & \\
\hline \multirow{2}{*}{$\begin{array}{l}\text { Brushing } \\
\text { frequency }\end{array}$} & $2 \mathrm{x}$ & \multirow{2}{*}{895} & \multirow{2}{*}{75.67} & \multirow{2}{*}{178} & 23.87 & \multirow{3}{*}{.740} \\
\hline & $\geq 3 \mathrm{x}$ & & & & 24.71 & \\
\hline TOTAL & & 1202 & 100.0 & 296 & 24.60 & \\
\hline
\end{tabular}

*Chi-square test for linear trends. **Numbers can be different because of the different number of respondents for that specific question.
Interexaminer weighted Kappa values ranged from 0.62 to 0.79 for DMFT/dmtf index.

\section{Statistical Analysis}

The data were double-typed using Epi-Info 6.04, and the consistency of the information was subsequently verified. Data were analyzed using STATA software version 10.0 (Stata Corporation, College Station, TX, USA). The associations between dental fear and independent variables were assessed using bivariate analysis $\left(\chi^{2}\right.$ and Fisher's exact test for categorical variables and $\chi^{2}$ of linear trend for ordinal variables) and multivariable analysis (Poisson regression with robust variance), estimating the prevalence ratios and their 95\% confidence intervals.

The variables that presented $p \leq 0.25$ in crude analysis were introduced in multivariate analysis. A conceptual model that makes the adjustment for possible confounding factors was developed for the multivariate analysis. In this model, variables were controlled for those on the same or on higher levels. Block 1 comprised socioeconomic and demographic variables of family and children. Block 2 included child habits and clinical variables. Block 3 comprised dental pain. Block 4 included dental visit.

\section{Ethical Considerations}

The Ethics Committee of the Dental School from Federal University of Pelotas approved this study (160/2010). The parents signed a written informed consent for their children's participation. The participating children received a kit containing toothbrush and dentifrice, and hygiene instruction. The results obtained in the oral examination were available in written form for each student. Those who needed dental treatment were referred to the Dental School.

\section{Results}

Among the 1,744 children invited to participate in this study, 1,325 (76.0\%) returned the questionnaire and informed consent form. Data from 123 children were lost during data collection 
Table 2. Association between dental fear and the independent variables according to adopted conceptual model (Poisson regression analysis, prevalence ratios (PR) with 95\% confidence intervals in parentheses)

\begin{tabular}{|c|c|c|c|c|c|}
\hline Variables & PRc & $(95 \%$ IC) & $\mathrm{p}$ value & PRa (95\% IC) & $\mathrm{p}$ value \\
\hline \multicolumn{6}{|c|}{ Block 1: Socioeconomic and demographic variables of family and children } \\
\hline Sex & & & $<.001$ & & $<.001$ \\
\hline Male & 1.0 & $(140-220)$ & & 171 (1 31-20) & \\
\hline Female & 1.79 & $(1.40-2.20)$ & & $1.11(1.51-2.02)$ & \\
\hline Age & & & .245 & * & \\
\hline 8 & 1.0 & \multirow{5}{*}{$\begin{array}{l}(.66-1.34) \\
(.63-1.30) \\
(.57-1.22) \\
(.53-1.25)\end{array}$} & & & \\
\hline 9 & .94 & & & & \\
\hline 10 & .90 & & & & \\
\hline 11 & .84 & & & & \\
\hline 12 & .81 & & & & \\
\hline Skin color & & \multirow{3}{*}{$(.94-1.55)$} & .134 & * & \\
\hline White & 1.0 & & & & \\
\hline Non White & 1.21 & & & & \\
\hline $\begin{array}{l}\text { Maternal } \\
\text { Schooling }\end{array}$ & & & .005 & $*$ & \\
\hline$\geq 8$ & 1.0 & \multirow{2}{*}{$(1.11-1.77)$} & & & \\
\hline$<8$ & 1.4 & & & & \\
\hline Family income & & & $<.001$ & & $<.001$ \\
\hline 4th (highest) & 1.0 & \multirow{4}{*}{$\begin{array}{c}(.86-1.91) \\
(.92-2.07) \\
(1.40-2.90)\end{array}$} & & 1.0 & \\
\hline $3 r d$ & 1.28 & & & $1.29(.86-1.92)$ & \\
\hline 2nd & 1.38 & & & $1.38(.92-2.07)$ & \\
\hline 1st (lowest) & 2.01 & & & $1.96(1.36-2.83)$ & \\
\hline
\end{tabular}

Block 2: child habits and clinical variables

\begin{tabular}{|c|c|c|c|c|c|}
\hline $\begin{array}{l}\text { Brushing } \\
\text { frequency }\end{array}$ & & & .773 & $* *$ & \\
\hline $\begin{array}{l}3 \text { or more } \\
\text { times }\end{array}$ & 1.0 & & & & \\
\hline 2 times & 1.03 & $(.82-1.31)$ & & & \\
\hline $\begin{array}{l}\text { Dental } \\
\text { Caries (D/d) }\end{array}$ & & & .005 & & .045 \\
\hline 0 & 1.0 & & & 1.0 & \\
\hline$>1$ & 1.42 & $(1.11-1.81)$ & & $1.32(1.01-1.72)$ & \\
\hline $\begin{array}{l}\text { Gengival } \\
\text { bleeding }\end{array}$ & & & .957 & ** & \\
\hline Absent & 1.0 & & & & \\
\hline Present & 1.01 & $(.76-1.33)$ & & & \\
\hline \multicolumn{6}{|l|}{ Block 3: Pain } \\
\hline Dental pain & & & .019 & & .188 \\
\hline Absent & 1.0 & \multirow{2}{*}{$(1.05-1.66)$} & & 1.0 & \\
\hline Present & 1.32 & & & $1.19(.92-1.54)$ & \\
\hline \multicolumn{6}{|c|}{ Block 4: Dental Visit } \\
\hline Dental visit & & & $<.001$ & & $<.001$ \\
\hline Yes & 1.0 & \multirow{2}{*}{$(1.56-2.50)$} & & 1.0 & \\
\hline No & 1.98 & & & $1.85(1.42-2.41)$ & \\
\hline
\end{tabular}

*Excluded after adjust according to first level variables. ${ }^{* *}$ Excluded after adjust according to first and second level variables. c: Crude analysis. a: Adjusted analysis because of absence from school or because they failed to answer the questionnaires or refused to undergo dental examination. A total of 1,202 were dentally examined and responded the questionnaire. Table 1 shows the sample distribution of dental fear according to sociodemographic characteristics and oral health behavior. Dental fear was reported by $296(24.6 \%)$ children.

In bivariate analyses, dental fear was greater in girls $(p<0.001)$, in children from mothers with fewer education years $(p=0.001)$ and from poorer families $(p<0.001)$. Dental fear was also greater in those who had dental caries (decayed teeth) $(p<0.001)$, those who experienced dental pain $(p=0.007)$ and those who had never visited the dentist $(p<0.001)$.

The crude and adjusted analyses of the association between dental fear and the independent variables are in Table 2. After the adjustment, girls remained more likely to have dental fear [PR=1.71 (Cl 95\%: 1.31-2.22)]. Family income was associated to dental fear prevalence comparing the first to the fourth quartile [PR=1.96 (Cl 95\%: 1.362.83)] and a higher prevalence of dental fear was found among poorer families. Children who presented decayed teeth $[\mathrm{PR}=1.32$ (Cl 95\%: 1.01-1.72) and who had never visited the dentist [PR $=1.85$ (Cl 95\%: 1.42-2.41) were more likely to have dental fear.

\section{Discussion}

The hypothesis tested in this study was confirmed, since the prevalence of dental fear was influenced by socioeconomic and demographic variables, clinical variables and the pattern of dental attendance. Dental fear was more prevalent in the kids who never visited the dentist, who had dental 
caries, in girls and in poorer families.

The prevalence of dental fear in this sample can be considered high compared to other studies with similar age range. In a Turkish study, where dental fear was assessed in children aged 7 to 10-years-old using the Children's Fear Survey Schedule - Dental Subscale (CFSS-DS) questionnaire, a prevalence of $14.5 \%$ was observed (15). Olak et al (6) assessed the prevalence of dental fear in 8 to 10-yearsold children in Estonia with the modified Dental Subscale of the Children's Fear Survey Schedule (CFSS-DS) where a single question was used to evaluate the children's general dental fear and the authors found low prevalence (6.1\%). The authors claimed these results are due to the use of an inadequate instrument to evaluate dental fear, which might have underestimated the real number of fearful children. The difference in dental fear prevalence among studies may be due to variations in culture and socioeconomic status among the studied populations and/or in methods used to assess dental fear (8).

Another study in Brazil (7) using the DAO to measure, the occurrence of fear among 5 to 12 years old found a prevalence of 39.4\%. The high prevalence found by these

$$
\stackrel{2}{\sim}
$$
children to be afraid of unknown situations and people. As the child's age increases new abilities are developed, the child feels more confident, has more self-control and gets ready to face the social environments (8).

In this population of 8-12 year old children the girls were found to be more fearful than boys. A previous report has already disclosed similar results (10). A reasonable explanation for this association is that due to cultural issues, girls probably feel more comfortable to express their feelings and confess their fears (16). Torriani et al (3) and Klingberg et al (8) were not able to find differences in fear scores between boys and girls. However, these studies included preschool children, which may be a confounding factor when evaluating the influence of gender in dental fear, since in young children cultural patterns are not yet stated (17). Studying the prevalence of dental pain in a birth cohort, there was no difference between boys and girls, however, when the same individuals were visited again at the age of 12, girls reported significantly higher levels of dental pain than boys (11). The authors explained that the socialization process and the establishment of cultural rules and patterns in older children led the boys to be more restricted to report subjective feelings like dental pain or dental fear, while the social pressure for girls is in the other direction. Thereby, further studies are necessary for a better understanding of the gender-dental fear relationship.

A significant association was found between family income and the presence of dental fear: children from poorer families had higher prevalence of dental fear. This result agrees with previous studies $(2,3)$ that found a higher prevalence of dental fear in preschoolers from low income families. Other studies have also found that anxious children tend to live in more deprived areas and come from lower social class than the non-anxious ones (18). Socioeconomic position has been evidenced as a strong marker for health indicators and those more deprived exhibited worse general and also oral health conditions. Children from poorer families have less access to dental care and experience higher loads of dental diseases (19), contributing probably to higher loads of dental fear.

Poor oral health outcomes are referred to be associated with childhood dental fear. The present results agree with previous studies $(3,6)$, showing that children with decayed teeth present a higher level of dental fear than those with no decay. Children exhibiting untreated dental caries are more prone to report dental pain and to have negative impact in their oral health related quality of life (20) and this can increase the chance of developing fear. Also results of this study showed a clear association between not going to the dentist with dental fear and it is beyond dispute that the lack of proper and regular dental care is related to a greater level of caries. To explain the association between dental fear and level of caries, the understanding of the dental fear's cycle is essential. Dental fear leads to the avoidance of dental visit, which consequently contributes to poorer dental health, thus, these individuals often make dental appointments for more invasive treatment or emergency reasons, contributing to the increase of dental fear (21). Evaluating the non-use of dental services, Goettems et al. (22) observed that around $1 / 4$ of the surveyed children had never visited the dentist and the prevalence of non-use was $62 \%$ higher in children who were afraid. The authors observed that regular visits to the dentist could provide an optimal climate for processing adverse events related to invasive dental treatments, decreasing the anxiogenic effects of a problematic visit. This is especially important because those more vulnerable, presenting high charge of disease and most needing the treatment are generally those with higher difficulty to access the dental service (23).

The motivation for the first dental attendance can be decisive for the development of fear. If this first visit happens for preventive procedures the prevalence of dental fear seems to be lower than when the dental visit is for emergency or curative procedures (3). These aspects reinforce the importance of early dental attention, preventing dental caries and consequently dental fear and the avoidance of dental appointments. DeDonno 
(24) demonstrated that those who were afraid of dental care had poorer oral hygiene practices, brushing and flossing less often. According to the author, oral health professionals have no opportunity to provide the children proper instruction on oral hygiene, since they refrain from dental offices. Beyond this, they may associate the oral practices with the negative feelings emerged from their dental experiences. This study did not find such association.

Noteworthy, another study conducted with this sample demonstrated that the socioeconomic conditions, the presence of decayed teeth, self-reported dental trauma history, occurrence of dental pain and/or dental fear influenced the oral health related quality of life in 8-10 years old Brazilian schoolchildren (20).

There are some limitations in the conducted study. The true causal relationship between the independent variables and the outcome is limited because of the employed cross-sectional study design. The parent's dental fear is an important variable influencing children's dental fear $(6,7)$ and it was not analyzed (not collected from the parents) in the study. Also, disabled children were excluded from the sample based on parent's or teacher's report, which may not present a proper diagnosis of disability.

It is important to emphasize that using a school-based sample allowed this study to obtain a better representation of children, because even dental avoiders are likely to attend school (10). In 2010, according to the Brazilian Institute of Geography and Statistics (IBGE), 97.6\% children aged between 7 and 9 years old were enrolled in schools in Brazil, corresponding to almost 9 million children.

Despite some researchers (6) considering inadequate to evaluate dental fear with one single question, the single item used in this study, the dental anxiety question (DAO), is listed in the literature as a relevant instrument, with good validity, specificity and sensitivity to assess dental anxiety $(13,25)$. This instrument has already been successfully used for many studies $(2,3,7)$, proving its reliability.

The high prevalence of dental fear indicates that it is a common problem among these schoolchildren. Dental fear had an association with dental experiences, showing that children who never visited the dentist and those who had caries were more afraid than the others. Also, an association with sociodemographic characteristics was found, being dental fear more frequently observed in girls and among families with lower socioeconomic status. Early dental care is still an important factor to prevent dental fear. Public health policies should establish prevention programs motivating routine dental visits.

\section{Resumo}

Este estudo transversal avaliou a prevalência do medo odontológico e fatores associados em escolares de 8 a 12 anos de idade, na cidade de
Pelotas, RS, Brasil. Alunos matriculados em 20 escolas públicas e privadas foram selecionados através de um delineamento de conglomerado em duplo estágio. As características sociodemográficas, a experiência odontológica da criança e os hábitos de higiene bucal foram avaliados por meio de questionários. 0 medo odontológico da criança foi avaliado através da Dental Anxiety Question. Examinadores calibrados avaliaram a presença de cárie dentária (CPOD) e o indice de sangramento gengival. Os dados foram analisados por meio de regressão de Poisson com variância robusta (razão de prevalência; 95\% intervalo de confiança). No total, 1202 crianças foram incluidas. A prevalência medo odontológico foi de $24,6 \%$. Após o ajuste, as meninas [ $R P=1,71$ (IC 95\%: 1,31-2,22)], as crianças de famílias mais pobres [RP=1,96 (IC 95\%: 1,36-2,83)], com lesões de cárie ( $D / d$ index $>0)[R P=1,32(I C 95 \%: 1,01-1,72)$ e as que nunca tinham ido ao dentista [RP=1,85 (IC 95\%: 1,42-2,41) permaneceram significativamente associadas ao medo dental. A prevalência de medo odontológico encontrada indica que este é um problema comum em escolares. 0 atendimento odontológico precoce e a prevenção de cárie são fatores importantes para evitar o medo.

\section{Acknowledgements}

The authors are grateful to Brazilian Agency - CNPq for the research funding (grant \#402350 provided to the PI - FFD). Also, authors would like to thank the Brazilian Agency CAPES for the scholarship provided to the first author. Moreover, the authors would like to thank Colgate for the oral hygiene kits distributed during fieldwork.

\section{References}

1. Marcenes W, Kassebaum NJ, Bernabe E, Flaxman A, Naghavi M, Lopez A, et al.. Global burden of oral conditions in 1990-2010: a systematic analysis. J Dent Res 2013;92:592-597.

2. Colares MMOV. The relationship between dental anxiety and dental pain in children aged 18 to 59 months: a study in Recife, PE, Brazil. Cad Saude Publica 2009;25:743-750.

3. Torriani DD, Ferro RL, Bonow ML, Santos IS, Matijasevich A, Barros AJ, et al.. Dental caries is associated with dental fear in childhood: findings from a birth cohort study. Caries Res 2014; 48:263-270.

4. Thomson WM, Broadbent JM, Locker D, Poulton R. Trajectories of dental anxiety in a birth cohort. Community Dent Oral Epidemiol 2009;37:209-219.

5. Oliveira MA, Bendo $C B$, Ferreira MC, Paiva SM, Vale MP, Serra-Negra JM. Association between childhood dental experiences and dental fear among dental, psychology and mathematics undergraduates in Brazil. Int J Environ Res Public Health 2012;9:4676-4687.

6. Olak J, Saag M, Honkala S, Nommela R, Runnel R, Honkala E, et al. Children's dental fear in relation to dental health and parental dental fear. Stomatologija 2013;15:26-31.

7. Colares V, Franca C, Ferreira A, Amorim Filho HA, Oliveira MC. Dental anxiety and dental pain in 5- to 12-year-old children in Recife, Brazil. Eur Arch Paediatr Dent 2013;14:15-19.

8. Klingberg G, Broberg AG. Dental fear/anxiety and dental behaviour management problems in children and adolescents: a review of prevalence and concomitant psychological factors. Int J Paediatr Dent 2007;17:391-406.

9. Bezabih S, Fantaye W, Tesfaye M. Dental anxiety: prevalence and associated factors, among children who visited Jimma University Specialized Hospital Dental Clinic. Ethiop Med J 2013;51:115-121.

10. Nakai Y, Hirakawa T, Milgrom P, Coolidge T, Heima M, Mori Y, et al.. The children's fear survey schedule-dental subscale in Japan. Community Dent Oral Epidemiol 2005;33:196-204.

11. Bastos JL, Peres MA, Peres KG, Araujo CL, Menezes AM. Toothache prevalence and associated factors: a life course study from birth to age 12 yr. Eur J Oral Sci 2008;116:458-466.

12. Goettems $M L$, Correa MB, Vargas-Ferreira $F$, Torriani DD, Marques $M$, Domingues MR, et al.. Methods and logistics of a multidisciplinary survey of schoolchildren from Pelotas, in the Southern Region of Brazil. Cad Saude Publica 2013;29:867-878. 
13. Neverlien PO. Assessment of a single-item dental anxiety question. Acta Odontol Scand 1990;48:365-369.

14. World Health Organization. Oral health surveys: basic methods. World Health Organization. 1987.

15. Akbay Oba A, Dulgergil CT, Sonmez IS. Prevalence of dental anxiety in 7- to 11-year-old children and its relationship to dental caries. Med Princ Pract 2009;18:453-457.

16. Schuller AA, Willumsen $T$, Holst D. Are there differences in oral health and oral health behavior between individuals with high and low dental fear? Community Dent Oral Epidemiol 2003;31:116-121.

17. Boeira GF, Correa MB, Peres KG, Peres MA, Santos IS, Matijasevich A, et al.. Caries is the main cause for dental pain in childhood: findings from a birth cohort. Caries Res. 2012;46:488-495.

18. Nuttall NM, Gilbert A, Morris J. Children's dental anxiety in the United Kingdom in 2003. J Dent 2008;36:857-860.

19. Goettems ML, Ardenghi TM, Romano AR, Demarco FF, Torriani DD. Influence of maternal dental anxiety on the child's dental caries experience. Caries Res 2012;46:3-8.

20. Schuch HS, Costa FS, Torriani DD, Demarco FF, Goettems ML. Oral health-related quality of life of schoolchildren: impact of clinical and psychosocial variables. Int J Paediatr Dent 2015;25:358-365.
21. Bhola R, Malhotra R. Dental procedures, oral practices, and associated anxiety: a study on late-teenagers. Osong Public Health Res Perspect. 2014;5:219-232.

22. Costa VP, Goettems ML, Oliveira $\sqcup$, Tarquinio SB, Torriani DD, Correa $M B$, et al.. Non-use of dental service by schoolchildren in southern Brazil: impact of socioeconomic, behavioral and clinical factors. Int J Public Health 2015;60:411-416.

23. Oliveira $\amalg$, Correa MB, Nascimento GG, Goettems ML, Tarquini SB, Torriani DD, et al.. [Inequalities in oral health: are schoolchildren receiving the Bolsa Familia more vulnerable?]. Rev Saude Publica 2013;47:1039-1047.

24. DeDonno MA. Dental anxiety, dental visits and oral hygiene practices. Oral Health Prev Dent 2012;10:129-133.

25. Viinikangas A, Lahti S, Yuan S, Pietila I, Freeman R, Humphris G. Evaluating a single dental anxiety question in Finnish adults. Acta Odontol Scand 2007;65:236-240.

Received October 9, 2016 Accepted February 2, 2017 